\title{
ISSR markers to assess genetic diversity of cultivated populations from artificial selection of Stevia rebaudiana (Bert.) Bertoni
}

\author{
Gilberto Codignole Luz ${ }^{1}$, Danuza Kelly Strioto ${ }^{2}$, Claudete Aparecida Mangolin ${ }^{3)}$ \\ and Maria de Fátima P.S. Machado*3) \\ 1) Postgraduate Program in Agronomy, State University of Maringá, Av. Colombo, 5790, 87020-900 Maringá PR Brazil \\ 2) Postgraduate Program in Genetics and Breeding, State University of Maringá, Av. Colombo, 5790, 87020-900 Maringá PR Brazil \\ 3) Department of Cell Biology and Genetics, State University of Maringá, Av. Colombo, 5790, 87020-900 Maringá PR Brazil
}

Artificial selection related with important agronomic characteristics of Stevia rebaudiana may cause genetic divergence and formation of genetically structured populations with genetic uniformity or diversity within cultivars. Current study employed inter simple sequence repeats of DNA (ISSR markers) to assess genetic diversity within and among a single cultivated population maintained through sexual propagation (SR1) and four cultivated populations generated by artificial selection and maintained by vegetative propagation (SR2SR5). Highest polymorphism rate was reported in SR1 (89.24\%), whilst the lowest rate of polymorphism occurred in SR2 (60.13\%). ISSR markers revealed that selection of plants with traits of vegetative-propagated interest may lead towards the generation of genetically more uniform DNA-level populations, while plants maintained by sexual propagation have high genetic variability. High estimated genetic divergence level indicated that the five areas of stevia form genetically structured populations. SR2 and SR4 are constituted by plants more homogeneous at DNA level for the selected characteristics than plants of SR3 and SR5 populations. Predominant and homogeneous genotypes selected at SR2 and SR4 areas could be valuable for tracing strategies to obtain stevia plants with the desirable agronomic characteristics through crosses between contrasting individuals in future breeding programs.

Key Words: stevia, sweet leaf herb, ISSR markers, genetic diversity, genetic uniformity.

\section{Introduction}

Stevia rebaudiana is an herbaceous perennial shrub, native to the Paraguay highlands (Brandle et al. 2002, see Yadav et al. 2011 for a review), currently produced and consumed in Japan, Brazil, Korea, Israel, United States of America, Argentina, China, Canada, Paraguay and Indonesia (Gantait et al. 2018). Stevioside and rebaudioside A, extracted from $S$. rebaudiana leaves, may be industrially produced as natural sweeteners, with sweetening power higher than that of sucrose (Singh and Rao 2005, Starratt and Gijzen 2004). Stevioside/rebaudioside A may be mixed in food products (candies, chocolates, cookies, ice cream, creams, juices, etc.) to reduce sugar consumption. Moreover, steviol glycosides, extracted from stevia leaves, are used to control Type II diabetes and blood pressure in hypertension patients (Gregersen et al. 2004, Hazali et al. 2014, Hsieh et al. 2003). Stevia leaves are also a rich source of antioxidants,

Communicated by Luigi Guarino

Received January 22, 2020. Accepted June 15, 2020.

First Published Online in J-STAGE on August 6, 2020.

*Corresponding author (e-mail: mfpsmachado@uem.br) antimicrobial and antifungal compounds (Lemus-Mondaca et al. 2012). The benefits to human health of compounds isolated from stevia leaves, emphasizing their role in inflammation, atherosclerosis and metabolic syndrome, have been reviewed by Gantait et al. (2015) and Rojas et al. (2018).

Genetic diversity in S. rebaudiana assessed by biochemical and molecular markers have been characterized as high. Isozymes analysis showed high genetic diversity in stevia cultivars (Carvalho et al. 2011). DNA sequences amplified by polymerase chain reaction (PCR) such as RAPD, ESTSSR and ISSR markers also have showed high polymorphism in collections (Dyduch-Siemińska et al. 2020, Sharma et al. 2016), accessions (Chester et al. 2013) and cultivars (Cosson et al. 2019) of stevia. Inter Simples Sequences Repeats of DNA (ISSR markers) are DNA sequences of 100-3000 bp, amplified by PCR, using a single primer (16-20 bp) constructed from microsatellite sequences (Zietkiewicz et al. 1994). Although ISSRs are dominant molecular markers, several informative sequences are generated by larger and specific ISSR primers (more than $10 \mathrm{bp}$ ), with larger anchorage regions for SSR loci. High repeatability in the pattern of amplified 
DNA segments is obtained with specific ISSR primers (Tsumura et al. 1996). ISSR primers have been used to evaluate the genetic fidelity of in vitro propagated plants of Stevia rebaudiana (Bert.) (Deshmukh et al. 2017, Lata et al. 2013, Singh et al. 2014, Soliman et al. 2014) and to assess genetic similarity among collections (Sharma et al. 2016) and different accessions (Garro-Monge et al. 2014, Heikal et al. 2008, Othman et al. 2018) of S. rebaudiana.

Although ISSR primers have been used to investigate genetic relationships among stevia accessions and collections (Garro-Monge et al. 2014, Heikal et al. 2008, Othman et al. 2018, Sharma et al. 2016), they have not been employed to evaluate whether there is any genetic diversity within local populations (accessions or collections). Knowledge on genetic diversity within each cultivated population and genetic structure of populations may be important to guide similar or differential management practices and for the development of more effective cultivation methods in the species. Current study hypothesizes that ISSR markers may be useful to evaluate genetic diversity within cultivated populations of stevia. Artificial selection related with important agronomic characteristics of stevia and the vegetative propagation as the predominant form of multiplication may lead to genetic divergence and formation of genetically structured cultivars with genetic uniformity or diversity within cultivars. Current study employed ISSR markers for assessing genetic diversity within and between a single cultivated population maintained through sexual propagation and four cultivated populations generated by artificial selection and maintained by vegetative propagation.

\section{Materials and Methods}

\section{Stevia cultivated populations}

The SR1 cultivated population of stevia (formed by approximately 250 plants) has been maintained since 1980 in the Experimental Farm of Iguatemi run by the State University of Maringá ( $\left.23^{\circ} 25^{\prime} \mathrm{S} ; 51^{\circ} 57^{\prime} \mathrm{W}\right)$. SR1 plants are remnants of a collection brought from Paraguay to Brazil in the early 1980s for domestication studies in the country. SR1 has been maintained by open pollination, and mainly through sexual propagation from seeds produced by plants in the same area and seeds introduced from different regions.

SR2, SR3, SR4 and SR5 cultivated populations (formed by approximately $50-100$ plants) have been generated by artificial selection from SR1 plants with different agronomic characteristics (taller, higher glycoside production, number of branches per plant and early flowering) and maintained by vegetative propagation in separate nurseries.

\section{DNA extraction from stevia leaves}

DNA was extracted from leaf tissues of 15 plants casually collected in each of the five cultivated populations (SR1, SR2, SR3, SR4 and SR5), following method described by Thomas and Scott (1993), with changes in the amount of tissues and volumes of reagents used. Leaves from each plant $(70 \mathrm{mg})$ were ground with liquid nitrogen and homogenized in $2 \mathrm{~mL}$ microtubes, with $1.250 \mu \mathrm{L}$ of extraction buffer, prepared with $0.25 \mathrm{M}$ Tris- $\mathrm{HCl} \mathrm{pH} 8.0$, $50 \mathrm{mM}$ EDTA, $0.1 \% \beta$-mercaptoethanol, $0.25 \mathrm{M} \mathrm{NaCl}$, $2.5 \%$ PVP-40. After homogenization, centrifugation was performed at $4^{\circ} \mathrm{C}$, for 10 minutes, at $4000 \times$ g. Supernatant was discarded and $700 \mu \mathrm{L}$ of extraction buffer prepared with $0.2 \mathrm{M}$ Tris $\mathrm{HCl}$ buffer, $\mathrm{pH} 7.0,50 \mathrm{mM}$ EDTA, $1 \% \beta-$ mercaptoethanol, $3 \%$ Sarcosil, $20 \%$ ethanol, $0.5 \mathrm{M} \mathrm{NaCl}$, $2 \%$ PVP-40 was added to each microtube. Samples were incubated in a water bath, at $37^{\circ} \mathrm{C}$, for 30 minutes and shaken every 5 minutes. After cooling to room temperature, $700 \mu \mathrm{L}$ chloroform:isoamyl alcohol (24:1) were added and the microtubes were stirred for 3 minutes. They were then centrifuged at room temperature for 12 minutes at $16000 \times \mathrm{g}$. After centrifugation, 0.54 multiplied by the volume of isopropanol was added in the recovered supernatant. Samples were centrifuged again, supernatant was discarded, and $200 \mu \mathrm{L} \mathrm{TE}(10 \mathrm{mM}$ Tris $/ \mathrm{HCl}$ and $1 \mathrm{mM}$ EDTA pH 8.0) were added to pellet (dried at room temperature). DNA was re-suspended and stored at $4^{\circ} \mathrm{C}$.

The next day, $2 \mu \mathrm{L}$ RNAse $\left(20 \mathrm{ng} \cdot \mu \mathrm{L}^{-1}\right)$ were added to each microtube and kept for 30 minutes, at room temperature. After 30 minutes, $100 \mu \mathrm{L}$ of $7.5 \mathrm{M}$ ammonium acetate were added and, after some inversions, samples were centrifuged at room temperature, for 12 minutes, at $16000 \times \mathrm{g}$. After centrifugation, 0.54 multiplied by the volume of isopropanol was added in the recovered supernatant and samples were stored overnight at $-20^{\circ} \mathrm{C}$. The following day, samples were centrifuged at room temperature for 12 minutes, at $16000 \times \mathrm{g}$. Pellet was washed with $300 \mu \mathrm{L}$ of $70 \%$ ice cold ethanol, centrifuged again $\left(12 \mathrm{~min} ; 4^{\circ} \mathrm{C}\right.$, at $16000 \times \mathrm{g}$ ), oven-dried at $37^{\circ} \mathrm{C}$ and re-suspended in $50 \mu \mathrm{L}$ TE. Samples were stored at $4^{\circ} \mathrm{C}$.

DNA quantification was performed using Picodrop Spectrophotometer (Pico 100-Version 4.0/21/03/11). DNA concentrations averaged between $33 \mathrm{ng} \cdot \mu \mathrm{L}^{-1}$ and $450 \mathrm{ng} \cdot \mu \mathrm{L}^{-1}$ per sample. After quantification, DNA samples were diluted at $10 \mathrm{ng} \cdot \mu \mathrm{L}^{-1}$ concentration.

\section{Amplification reactions using inter simple sequence re- peat primers}

Amplifications were performed using volumes of $20 \mu \mathrm{L}$ containing $15 \mathrm{ng}$ of genomic DNA, reaction buffer $(10 \mathrm{mM}$ Tris- $\mathrm{HCl}, \mathrm{pH} 8.8), 2.4 \mathrm{mM} \mathrm{MgCl}, 0.1 \mathrm{mM}$ each of dATP, dGTP, dCTP, and dTTP, $0.25 \mu \mathrm{M}$ primer, 1 unit of Taq Polymerase Platinum (Invitrogen) and Milli-Q water, to bring the reaction to the final volume.

Eleven ISSR primers (Table 1), previously selected from 38 ISSR primers (from our laboratory's ISSR primers bank), showing well-defined DNA segments in gel (clearcut, accurate and separate bands on the gel) were used with DNA samples of stevia. DNA amplification occurred with initial denaturation at $94^{\circ} \mathrm{C}$, for $5 \mathrm{~min}$, followed by 
Table 1. ISSR primer nucleotide sequences, annealing temperature (AT), number of segments per primer amplified (NSA) and number of segments per primer polymorphic (NSP) in Stevia rebaudiana plants

\begin{tabular}{lcccc}
\hline \hline Primers & Sequences $\left(5^{\prime} \rightarrow 3^{\prime}\right)$ & AT $\left({ }^{\circ} \mathrm{C}\right)$ & NSA & NSP \\
\hline ISSR-1 & $(\mathrm{AC})_{8} \mathrm{TT}$ & 51 & 15 & 15 \\
HB-11 & $(\mathrm{GT})_{6} \mathrm{CC}$ & 50 & 14 & 12 \\
HB-12 & $(\mathrm{CAC})_{3} \mathrm{GC}$ & 50 & 16 & 15 \\
ISSR-23 & $(\mathrm{AG})_{8} \mathrm{AT}$ & 51.5 & 12 & 12 \\
UBC-807 & $(\mathrm{AG})_{8} \mathrm{~T}$ & 50.5 & 15 & 15 \\
UBC-812 & $\left(\mathrm{AG}_{8}\right) \mathrm{A}$ & 51 & 13 & 12 \\
ISSR-822 & $(\mathrm{TC})_{8} \mathrm{~A}$ & 51 & 15 & 12 \\
ISSR-825 & $(\mathrm{AC})_{8} \mathrm{~T}$ & 51 & 12 & 8 \\
ISSR-826 & $(\mathrm{AC})_{8} \mathrm{C}$ & 51 & 15 & 15 \\
UBC-827 & $(\mathrm{AC})_{8} \mathrm{G}$ & 51 & 16 & 15 \\
ISSR-17898A & $(\mathrm{CA})_{6} \mathrm{AC}$ & 51 & 15 & 13 \\
\hline TOTAL & & & 158 & 144 \\
\hline
\end{tabular}

34 cycles at $94^{\circ} \mathrm{C}$ for $1 \mathrm{~min}$, with annealing at $50-51.5^{\circ} \mathrm{C}$ for $1 \mathrm{~min}$ and extension at $72^{\circ} \mathrm{C}$ for $1 \mathrm{~min}$ and $30 \mathrm{~s}$. Afterwards, a final extension was carried out at $72^{\circ} \mathrm{C}$, for $7 \mathrm{~min}$. Polymerase chain reaction (PCR) was performed with a Techne TC-512 thermal cycler.

Electrophoresis was performed with $1.5 \%$ agar gel and $0.5 \times$ TBE buffer $(44.5 \mathrm{mM}$ Tris-boric acid and $1 \mathrm{mM}$ EDTA) at $60 \mathrm{~V}$, for $4 \mathrm{~h}$. After electrophoresis, the gels were stained with ethidium bromide at $0.5 \mu \mathrm{g} \cdot \mathrm{mL}^{-1}$ and images were taken with a Molecular Image LOCCUS L-PIX - HE by Picasa 3. The size of the PCR fragments was determined with a $1 \mathrm{~kb}$ DNA Ladder (Invitrogen).

\section{Analysis of polymorphism}

Polymorphisms from ISSR loci were analyzed as dominant markers [(1) presence and (0) absence of amplified DNA segments]. Polymorphisms from ISSR markers were analyzed with POPGENE 1.32 (Yeh et al. 1999) to estimate the genetic divergence between SR1, SR2, SR3, SR4 and SR5 cultivated populations of stevia. FreeTree software (Pavlícek et al. 1999) was used to perform bootstrap analysis and compare plant specimens among the five cultivated areas of stevia (SR1-SR5). Distance similarity matrix was computed with UPGMA (Sneath and Sokal 1973), followed by Jaccard's clustering method, with resampling analysis using 1000 replications. A dendrogram was constructed, based on a reference tree by TreeView program (Page 2001).

Polymorphisms from ISSR markers were also analyzed using StruCture software 2.0 (Pritchard and Wen 2003), which evaluates the level of genetic admixture between the 75 phenotypic variants of $S$. rebaudiana. The genotypes were clustered, with number of clusters (K) ranging between 2 and 5, and were tested using the admixture model with a burn-in period of 10.000 repeats, followed by 100.000 Markov Chain Monte Carlo (MCMC) repeats, considering the presence and absence of alleles across the sample. The true number of populations $(\mathrm{K})$ is often identified by maximal value of $\Delta(\mathrm{K})$ returned by the software. The most probable number $(\mathrm{K})$ of subpopulations was identified as described by Evanno et al. (2005). The graphical output display of the STRUCTURE results was taken as input data using Structure Harvester, a website and software that visualize STRUCTURE output and implement the Evanno method (Earl and vonHoldt 2012) to display a graphical representation.

\section{Results}

One hundred and fifty-eight DNA segments were amplified by 11 ISSR primers (Table 1 ). The number of bands produced for each primer ranged between 12 and 16, with an average of 14.3 amplicons per primer. The size of the amplified products ranged between 500 and $4.000 \mathrm{bp}$.

Primers HB-12 and UBC-827 generated the highest number of amplified segments (16), while the highest number of polymorphic segments (15) in the five cultivated areas of stevia was detected in ISSR-1, HB-12, UBC-807, UBC-826 and UBC-827 primers (Table 1). Thus, primers ISSR-1, HB-12, UBC-807, UBC-826 and UBC-827 may be preferred to compare $S$. rebaudiana genome samples. Fig. 1 shows the amplified segments of DNA from the SR3 and SR4 populations of $S$. rebaudiana using the HB-12 primer.

The highest polymorphism rate was reported in SR1 (89.24\%), whilst the lowest rate of polymorphism occurred in SR2 (60.13\%). Polymorphism rates in SR3, SR4 and

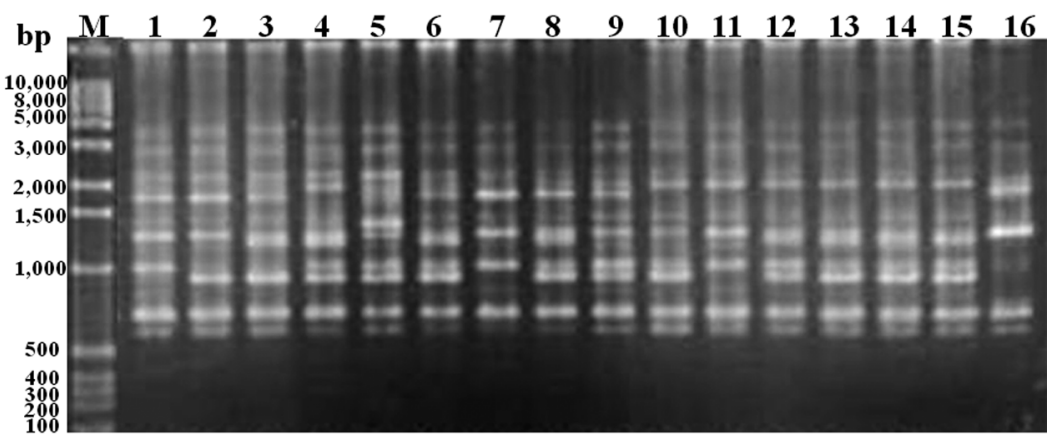

Fig. 1. Amplified segments of DNA from the SR3 (samples 1-15) and SR4 (sample 16) populations of Stevia rebaudiana using the HB-12 primer. " $\mathrm{M}$ " is the DNA ladder $1 \mathrm{~Kb}$ molecular weight marker. 
SR5 cultivated areas of stevia were $72.15 \%, 63.29 \%$ and $83.54 \%$, respectively (Table 2 ).

The estimated genetic divergence level for ISSR markers of $S$. rebaudiana samples SR1, SR2, SR3, SR4 and SR5, represented by $\mathrm{G}_{\mathrm{ST}}$, was high $\left(\mathrm{G}_{\mathrm{ST}}=0.2373\right)$. The genetic similarity value estimated by Nei's coefficient (Nei 1972) showed that samples SR1 and SR5 were the most similar $(I=0.9233)$, while samples SR2 and SR4 were the least similar $(\mathrm{I}=0.7523)$ (Table 3$)$.

Dendrogram was built from data of the 11 ISSR primers according to Jaccard coefficient and drawn from a reference tree by TreeView program (Page 2001). Dendrogram showed heterogeneous groups formed by mixture of plants from SR1 and SR5 and homogeneous groups formed by plants from SR2 and SR3 cultivated populations (Fig. 2).

Fig. 3 shows the clustering of the 75 plants of the five stevia cultivated populations according to a model-based Bayesian algorithm. Each bar in the graph represents a plant and its inferred proportion of genome admixture. Colors represent three different clusters corresponding to the plants' different proportions in each group. Optimal K value, determined by Bayesian analysis, indicates that the 75 plants were grouped into 3 subpopulations $(\Delta \mathrm{K} 2=0.00$; $\Delta \mathrm{K} 3=127.0973 ; \Delta \mathrm{K} 4=70.3607 ; \Delta \mathrm{K} 5=0.000)$. The bar plot obtained for $\mathrm{K}$ value $(\mathrm{K}=3 ; \Delta \mathrm{K}=127.0973)$ and results were consistent with the evidence that $89.56 \%$ of the plants from SR1 are within the blue group; $89.84 \%$ of the plants from SR2 are within the red group; $72.13 \%$ of the plants from SR3 are within the blue group; $91.6 \%$ of the plants from SR 4 are within the green group, while $54.5 \%$ of
Table 2. Number of DNA polymorphic segments (NPS), polymorphism (\% P), and Nei's genetic diversity (Nei 1973) (h) in SR1, SR2, SR3, SR4 and SR5 cultivated populations (CP) of Stevia rebaudiana using ISSR primers

\begin{tabular}{lrcc}
\hline \hline CP & NPS & $\% \mathrm{P}$ & $\mathrm{h}$ \\
\hline SR1 & 141 & 89.24 & 0.3511 \\
SR2 & 95 & 60.13 & 0.2209 \\
SR3 & 114 & 72.15 & 0.2746 \\
SR4 & 100 & 63.29 & 0.2366 \\
SR5 & 132 & 83.54 & 0.3424 \\
\hline Total & 147 & 93.04 & 0.3736 \\
\hline
\end{tabular}

Table 3. Similarity matrix between cultivated populations (SR1, SR2, SR3, SR4 and SR5) of Stevia rebaudiana

\begin{tabular}{lccccc}
\hline \hline CP & SR1 & SR2 & SR3 & SR4 & SR5 \\
\hline SR1 & $* * *$ & 0.8137 & 0.8699 & 0.8316 & 0.9233 \\
SR2 & 0.2061 & $* * *$ & 0.8414 & 0.7523 & 0.8867 \\
SR3 & 0.1394 & 0.1727 & $* * *$ & 0.8164 & 0.8889 \\
SR4 & 0.1844 & 0.2846 & 0.2029 & $* * *$ & 0.8573 \\
SR5 & 0.0798 & 0.1203 & 0.1178 & 0.1540 & $* * *$ \\
\hline
\end{tabular}

the plants from SR5 are also within the blue group (Table 4). The bar plot shows that less than $20 \%$ of SR1 (10\%), SR2 (10.1\%), SR4 (8.4\%) plants share all the two or three groups, whereas in plants from SR5, the mixture of 2-3 groups alleles in each plant was greater than $20 \%$ (Fig. 2). The bar plot also shows ISSR segment groups selected from stevia plants of the SR1 cultivated population

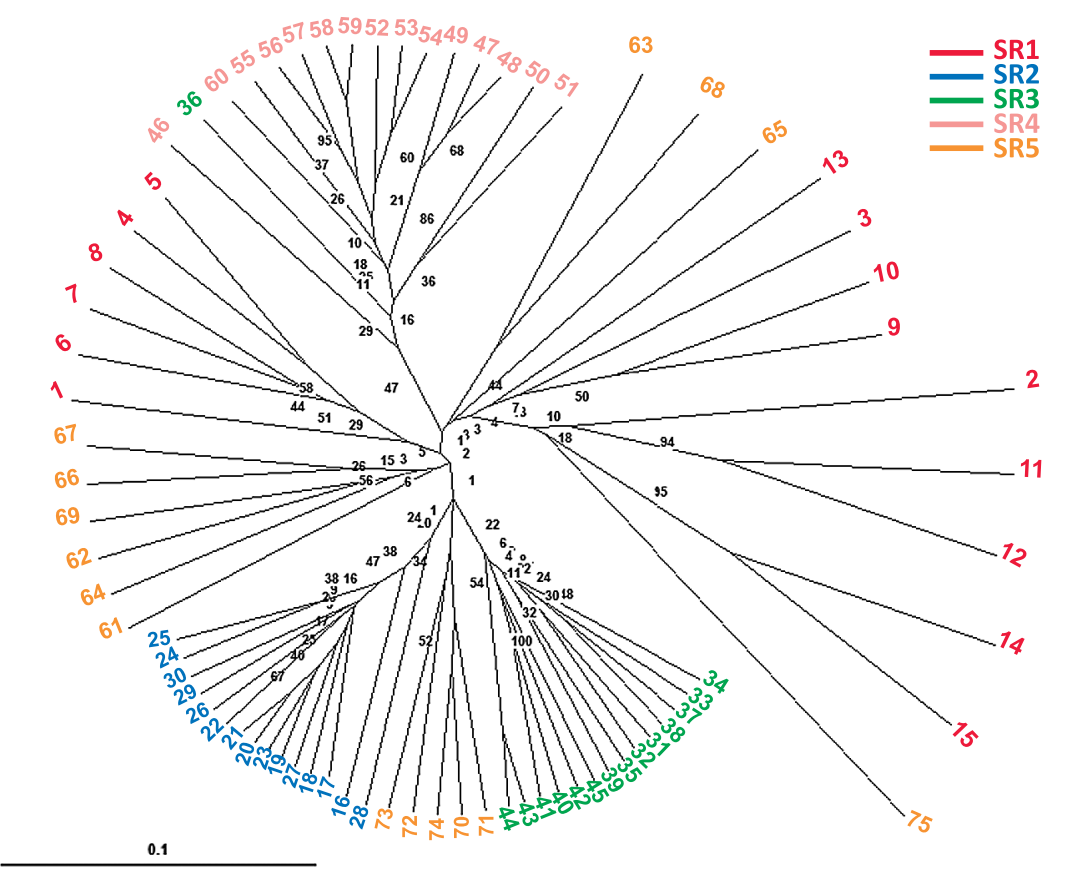

Fig. 2. Dendrogram generated by UPGMA clustering method from analysis of individual plants of Stevia rebaudiana cultivated populations: SR1 (1-15), SR2 (16-30), SR3 (31-45), SR4 (46-60), and SR5 (61-75) constructed from 11 ISSR primers (ISSR-1, HB-11, HB-12, ISSR-23, UBC-807, UBC-812, ISSR-822, ISSR-825, UBC-826, UBC-827 and ISSR-17898A) data, according to the Jaccard coefficient, and drawn from a reference tree by TreeView program (Page 2001). Number beside node indicates relative bootstrap frequency (\%). 


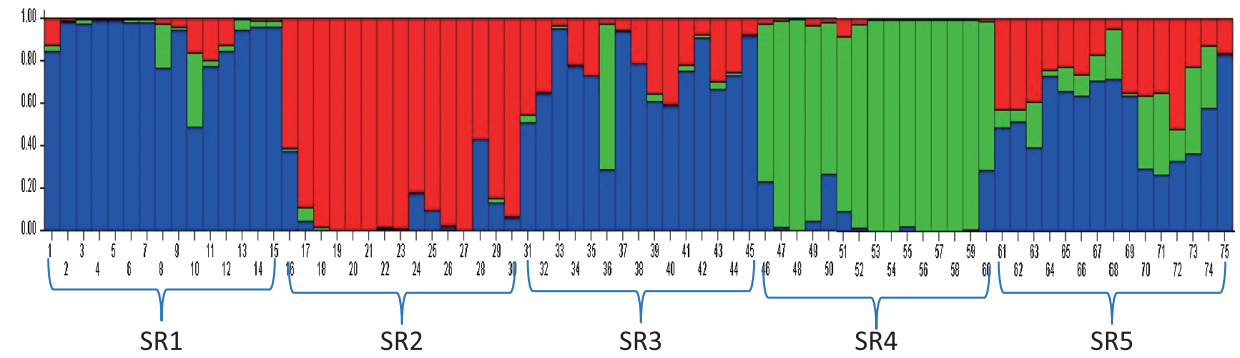

Fig. 3. Clustering of 75 plants of five Stevia rebaudiana cultivated populations (SR1-SR5) following a model-based Bayesian algorithm. Each plant is represented by a single vertical bar broken in $\mathrm{K}$ colored segments $(\mathrm{K}=3)$, with lengths proportional to each of the $\mathrm{K}$ inferred clusters. Each color represents the proportion of DNA segments for each individual, represented by a vertical bar, in each group.

Table 4. Proportion of 75 plants of five Stevia rebaudiana cultivated populations (SR1, SR2, SR3, SR3, SR4 and SR5) in each group $(\mathrm{K}=3)$ analyzed with STRUCtURE software 2.0 (Pritchard and Wen 2003)

\begin{tabular}{lccc}
\hline \hline & \multicolumn{3}{c}{ Groups } \\
\hline Populations/(N) & Red & Green & Blue \\
\hline SR1 (15) & 0.0485 & 0.0556 & 0.8956 \\
SR2 (15) & 0.8984 & 0.0102 & 0.0912 \\
SR3 (15) & 0.2178 & 0.0608 & 0.7213 \\
SR4 (15) & 0.0154 & 0.9160 & 0.0686 \\
SR5 (15) & 0.2836 & 0.1713 & 0.5450 \\
\hline
\end{tabular}

$\mathrm{N}=$ number of plants.

for the formation of SR2, SR3, SR4 and SR5 populations formed by vegetative propagation. Plants in the red and green groups of the cultivated population SR1 were selected and formed predominant and homogeneous groups in SR2 (89.84\%) and SR4 (91.6\%) cultivated areas, respectively.

\section{Discussion}

A higher polymorphism rate reported in SR1 plants may be expected rather than in SR2, SR3, SR4 and SR5 plants. Plants from SR1 population are sexually propagated and maintained with open pollination for over three decades in the cultivation area, while SR2, SR3, SR4 and SR5 populations were generated by artificial selection from plants SR1, and maintained by vegetative propagation in order to obtain stevia plants with desirable agronomic characteristics (taller, higher glycoside production, number of branches per plant and early flowering). ISSR are indicated markers to show that the selection of plants with traits of vegetative-propagated interest may lead towards the generation of genetically more uniform DNA-level populations, while plants propagated by seeds have high genetic variability due outcrossing. Open pollination by insects and self-incompatibility have been reported in studies with stevia (Maiti and Purohit 2008, Oddone 1997, Özyigit et al. 2015, Yadav et al. 2014).

High $\mathrm{G}_{\mathrm{st}}$ rate is due to differential polymorphism of some ISSR segments in different samples and indicates that the five SR1, SR2, SR3, SR4, and SR5 samples of stevia form genetically structured populations. According to Wright (1978), $\mathrm{G}_{\mathrm{ST}}$ rates between 0.15 and 0.25 indicate high level of interpopulation divergence or high level of genetic differentiation between populations. $\mathrm{G}_{\mathrm{ST}}$ is defined as the proportion of genetic diversity that resides among populations and was estimated using the Nei method (Nei 1973) with POPGENE 1.32 (Yeh et al. 1999). It is equivalent to Wright (1951) $\mathrm{F}_{\mathrm{ST}}$ when there are only two alleles at a locus, and, in the case of multiple alleles, $\mathrm{G}_{\mathrm{ST}}$ is equivalent to the weighted average of $\mathrm{F}_{\mathrm{ST}}$ for all alleles (Nei 1973).

Although the agronomic characteristics of each SR2, SR3, SR4 and SR5 cultivated population generated by artificial selection have not been assigned in current study, the use of ISSR in the identification of genetic diversity within each cultivated population showed that SR2 and SR4 are constituted by more homogeneous plants at DNA level for the selected characteristics than plants of SR3 and SR5 populations. Lower ISSR polymorphism was observed in cultivated populations SR2 (60.13\%) and SR4 (63.29\%) than in populations SR3 (72.15\%) and SR5 (83.54) (Table 2).

The use of ISSR in the identification of genetic diversity within cultivated areas of stevia is relevant since molecular identification is more reliable than morphological characterization, highly affected by the environment. ISSR markers have only been used to investigate the relationship between accessions and between collections of stevia (Garro-Monge et al. 2014, Heikal et al. 2008, Othman et al. 2016, 2018, Sharma et al. 2016). Genetic diversity within each accession or collection has not been revealed by ISSR markers. Molecular polymorphism within landraces and cultivated populations of stevia have been investigated by esterase isozymes and expressed sequence tags (EST) in simple sequence repeats (SSRs) as markers (Carvalho et al. 2011, Cosson et al. 2019). Genetic diversity in esterase loci within of $S$. rebaudiana cultivated populations which were subjected to artificial selection pressure of characteristics such as greater height or early flowering, demonstrated that this procedure leads towards the fixation of different alleles and different esterase phenotype patterns (Carvalho et al. 2011). Likewise, as was observed in our study with ISSR markers, the selection pressure adopted by Carvalho et al. 
(2011) to form crops with characteristics of interest resulted in genetically structured. EST-SSR also revealed higher genetic diversity in landraces than in the cultivated populations (Cosson et al. 2019).

The predominant agronomic characteristics and homogeneous DNA genotypes selected in SR2 and SR4 populations could be significant for tracing strategies to obtain stevia plants with the desirable agronomic characteristics (for example, taller plants with higher rebaudioside contents) through crosses among contrasting individuals in future breeding programs.

On the other hand, the high level of genetic diversity in SR5 cultivated population, also founded on SR1, indicates that the selection for the characteristic of interest resulted in a genetically non-uniform (heterogeneous) culture. SR5 may still represent a source of material to select plants with desirable agronomic characteristics. High level of genetic diversity may express itself in the form of different morphology, anatomy, physiological behavior or biochemical features. Diversity in plant genetic resources provides opportunity for plant breeders to develop new and improved cultivars with desirable characteristics (Bhandari et al. 2017). Genetic diversity within and between crop plant species permits the breeders to select superior genotypes either to be directly used as new variety or to be used as parent in hybridization programmes.

\section{Author Contribution Statement}

GCL and DKS selected and collected plant material for present study and carried out the vegetative propagation of the four SR2, SR3, SR4 and SR5 cultivated populations. GCL, DKS and CAM carried out molecular analysis with ISSR primers, performed the genetic data analysis and drafted the manuscript. GCL, CAM and MFPSM participated in the initial discussion on the project and contributed towards the sampling selection of $S$. rebaudiana. MFPSM conceived and supervised the project, assisted in the analysis of data, discussed results and contributed towards the drafting of the manuscript. All authors have read and approved the final manuscript.

\section{Acknowledgments}

The authors would like to thank the Coordination for the Upgrading of Higher Education Personnel (Coordenação de Aperfeiçoamento de Pessoal de Nível Superior-CAPES) [Finance Code 001].

\section{Literature Cited}

Bhandari, H.R., A.N. Bhanu, K. Srivastava, M.N. Singh and A. Hemantaranjan (2017) Assessment of genetic diversity in crop plants-an overview. Adv. Plants Agric. Res. 7: 279-286.

Brandle, J.E., A. Richman, A.K. Swanson and B.P. Chapman (2002) Leaf ESTs from Stevia rebaudiana: A resource for gene discovery in diterpene synthesis. Plant Mol. Biol. 50: 613-622.

Carvalho, V.M., C.A. Marochio, C.A. Mangolin and M.F.P.S. Machado (2011) The use of esterase polymorphism for analysis of the genetic diversity and structure of stevia (Stevia rebaudiana Bert. Bertoni) populations. Biochem. Syst. Ecol. 39: 594-599.

Chester, K., E.T. Tamboli, R. Parveen and S. Ahmad (2013) Genetic and metabolic diversity in Stevia rebaudiana using RAPD and HPTLC analysis. Pharm. Biol. 51: 771-777.

Cosson, P., C. Hastoy, L.E. Errazzu, C.J. Budeguer, P. Boutié, D. Rolin and V. Schurdi-Levraud (2019) Genetic diversity and population structure of the sweet leaf herb, Stevia rebaudiana B., cultivated and landraces germplasm assessed by EST-SSRs genotyping and steviol glycosides phenotyping. BMC Plant Biol. 19: 436.

Deshmukh, N., R. Talkal and N. Khan (2017) In vitro propagation and determination of genetic stability of micropropagated plants of Stevia rebaudiana. IJARIIE (International Journal of Advance Research and Innovative Ideas in Education) 3: 884-894.

Dyduch-Siemińska, M., A. Najda, J. Gawroński, S. Balant, K. Świca and A. Żaba (2020) Stevia rebaudiana Bertoni, a source of highpotency natural sweetener-biochemical and genetic characterization. Molecules 25: 767.

Earl, D.A. and B.M. vonHoldt (2012) Structure Harvester: a website and program for visualizing STRUCTURE output and implementing the Evanno method. Conserv. Genet. Resour. 4: 359-361.

Evanno, G., S. Regnaut and J. Goudet (2005) Detecting the number of clusters of individuals using the software STRUCTURE: a simulation study. Mol. Ecol. 14: 2611-2620.

Gantait, S., A. Das and N. Mandal (2015) Stevia: A comprehensive review on ethnopharmacological properties and in vitro regeneration. Sugar Tech 17: 95-106.

Gantait, S., A. Das and J. Banerjee (2018) Geographical distribution, botanical description and self-incompatibility mechanism of genus Stevia. Sugar Tech 20: 1-10.

Garro-Monge, G., K. Jiménez-Quesada and S. Alvarenga-Venutolo (2014) Caracterización genética molecular de materiales procesados de Stevia rebaudiana utilizando la técnica de microssatélites. Tecnología en Marcha 27: 32-40.

Gregersen, S., P.B. Jeppesen, J.J. Holst and K. Hermansen (2004) Antihyperglycemic effects of stevioside in type 2 diabetic subjects. Metab. Clin. Exp. 53: 73-76.

Hazali, N., A. Mohamed, M. Ibrahim, M. Masri, K.A. Isa, N. Nor, M.K. Ayob and F.N.M. Fadzlan (2014) Effect of acute Stevia consumption on blood glucose response in healthy Malay young adults. Sains Malaysiana 43: 649-654.

Heikal, A.H., O.M. Badawy and A.M. Hafez (2008) Genetic relationships among some stevia (Stevia Rebaudiana Bertoni) accessions based on ISSR analysis. Res. J. Cell Mol. Biol. 2: 1-5.

Hsieh, M.H., P. Chan, Y.M. Sue, J.C. Liu, T.H. Liang, T.Y. Huang, B Tomlinson, M.S.S. Chow, P.F. Kao and Y.J. Chen (2003) Efficacy and tolerability of oral stevioside in patients with mild essential hypertension: a two-year, randomized, placebo-controlled study Clin. Ther. 25: 2797-2808.

Lata, H., S. Chandra, N. Techen, Y.-H. Wang and I.A. Khan (2013) Molecular analysis of genetic fidelity in micropropagated plants of Stevia rebaudiana Bert. using ISSR marker. Am. J. Plant Sci. 4: 964-971.

Lemus-Mondaca, R., A. Vega-Gálvez, L. Zura-Bravo and K. Ah-Hen (2012) Stevia rebaudiana Bertoni, source of a high-potency natural sweetener: A comprehensive review on the biochemical, nutritional and functional aspects. Food Chem. 132: 1121-1132.

Maiti, R.K. and S.S. Purohit (2008) Stevia: A miracle plant for human 
health Agrobios (India) Jodhpur India.

Nei, M. (1972) Genetic distance between populations. Am. Nat. 106: 283-292.

Nei, M. (1973) Analysis of gene diversity in subdivided populations. Proc. Natl. Acad. Sci. USA 70: 3321-3323.

Oddone, B. (1997) How to Grow Stevia. Technical Manual. Guarani Botanicals, Pawtucket, CT.

Othman, H.S., Z. Zainuddin and M. Osman (2016) Assessment of genetic diversity and hybrid identification in Stevia using Inter Simple Sequence Repeat (ISSR) markers. Transactions of Persatuan Genetik Malaysia 3: 157-162.

Othman, H.S., M. Osman and Z. Zainuddin (2018) Genetic variabilities of Stevia rebaudiana Bertoni cultivated in Malaysia as revealed by morphological, chemical and molecular characterisations. AGRIVITA J. Agric. Sci. 40: 267-283.

Özyigit, Y., E. Uçar and K. Turgut (2015) The effect of different pollination methods on seed yield and germination features in Stevia rebaudiana Bertoni. Turk. J. Agric. Res. 2: 114-117.

Page, R.D.M. (2001) TreeView (Win 32). Version 1.6.6. http://taxonomy. zoology.gla.ac.uk/rod/rod.html.

Pavlícek, A., S. Hrdá and J. Flegr (1999) FreeTree-freeware program for construction of phylogenetic trees on the basis of distance data and bootstrap/jackknife analysis of the tree robustness. Application in the RAPD analysis of genus Frenkelia. Folia Biol. (Praha) 45: 97-99.

Pritchard, J.K. and W. Wen (2003) Documentation for Structure software: Version 2. Available at http://pritch.bsd.uchicago.edu.

Rojas, E., V. Bermúdez, Y. Motlaghzadeh, J. Mathew, E. Fidilio, J. Faria, J. Rojas, M.C. de Bravo, J. Contreras, L.P. Mantilla et al. (2018) Stevia rebaudiana Bertoni and its effects in human disease: emphasizing its role in inflammation, atherosclerosis and metabolic syndrome. Curr. Nutr. Rep. 7: 161-170.

Sharma, N., R. Kaur and V. Era (2016) Potential of RAPD and ISSR markers for assessing genetic diversity among Stevia rebaudiana Bertoni accessions. Indian J. Biotechnol. 15: 95-100.

Singh, P., P. Dwivedi and N. Atri (2014) In vitro shoot multiplication of Stevia and assessment of stevioside content and genetic fidelity of the regenerants. Sugar Tech 16: 430-439.
Singh, S.D. and G.P. Rao (2005) Stevia: The herbal sugar of $21^{\text {st }}$ century. Sugar Tech 7: 17-24.

Sneath, P.H.A. and R.R. Sokal (1973) Numerical taxonomy. San Francisco, CA: Freeman.

Soliman, H.I.A., E.M.R. Metwali and O.A.-H. Almaghrabi (2014) Micropropagation of Stevia rebaudiana Betroni and assessment of genetic stability of in vitro regenerated plants using inter simple sequence repeat (ISSR) marker. Plant Biotechnol. 31: 249-256.

Starratt, A.N. and M. Gijzen (2004) Stevia Rebaudiana-Its Biological, Chemical and Agricultural Properties. Agriculture and AgriFood Canada, Southern Crop Protection and Food Research Centre, Sandford St., London, Ontario.

Thomas, M.R. and N.S. Scott (1993) Microsatellite repeats in grapevine reveal DNA polymorphisms when analysed as sequence-tagged sites (STSs). Theor. Appl. Genet. 86: 985-990.

Tsumura, Y., K. Ohba and S.H. Strauss (1996) Diversity and inheritance of inter-simple sequence repeat polymorphisms in Douglasfir (Pseudotsuga menziesii) and sugi (Cryptomeria japonica). Theor. Appl. Genet. 92: 40-45.

Wright, S. (1951) The genetical structure of populations. Ann. Eugen. 15: 323-354.

Wright, S. (1978) Variability within and among populations. Chicago: University of Chicago Press, p. 580.

Yadav, A.K., S. Singh, D. Dhyani and P.S. Ahuja (2011) A review on the improvement of stevia [Stevia rebaudiana (Bertoni)]. Can. J. Plant Sci. 91: 1-27.

Yadav, A.K., S. Singh and R. Rajeev (2014) Self-incompatibility evidenced through scanning electron microscopy and pollination behaviour in Stevia rebaudiana. Indian J. Agricult. Sci. 84: 93100.

Yeh, F.C., T.Y.Z. Boyle and J.M. Xiyan (1999) POPGENE Version 1.32: Microsoft Window-based freeware for population genetic analysis. University of Alberta and Center for International Forestry Research.

Zietkiewicz, E., A. Rafalski and D. Labuda (1994) Genome fingerprinting by simple sequence repeat (SSR)-anchored polymerase chain reaction amplification. Genomics 20: 176-183. 